\title{
Experimental Evaluation of Galling Under Press Hardening Conditions
}

\author{
Liang Deng $^{1} \cdot$ Leonardo Pelcastre ${ }^{2} \cdot$ Jens Hardell ${ }^{2} \cdot$ Braham Prakash $^{2} \cdot$ Mats Oldenburg $^{1}$
}

Received: 26 November 2017 / Accepted: 30 April 2018 / Published online: 26 June 2018

(c) The Author(s) 2018

\begin{abstract}
Severe adhesion, also referred to as galling, is a critical problem in press hardening, especially in stamping tools used for hot forming of Al-Si-coated ultra-high strength steel. Galling is known to develop rapidly on the tool surface and it negatively affects the quality of the formed products. Earlier research on this topic has focused on the galling initiation. However, studies on the galling development during extended sliding and the corresponding quantitative measurement still lack depth. In the present study, a tribological test is established to study the galling development under press hardening conditions. The tribological test set-up aims to simulate extended sliding between the Al-Si-coated boron steels and the tool die material. The contact conditions in the interface are studied by a numerical model of the tribological test. The friction coefficients and material transfer are discussed taking into account the variation of the different test conditions. Using the results from the tribological tests, the galling simulation is performed in the numerical model. A geometry-updated sample based on the galling (transferred material build-up) height is simulated and the consequent pressure fluctuation is obtained in the numerical model. This contributes to the explanation of the severe transferred material accumulation during the test.
\end{abstract}

Keywords Galling evolution · Contact conditions · FE-simulation · Tribological test · Tribological behaviour

\section{Introduction}

The press hardening processes involve heating, forming and quenching. A boron steel sheet is heated in a furnace until fully austenitized, followed by transferring to stamping tools. The stamping tools form the workpiece taking the advantage of a good formability of the boron steel at high temperatures. Subsequently, the workpiece is cooled down in the tooling section itself to obtain the transformation to martensite, which provides a yield strength between 1000 and $1200 \mathrm{MPa}$ [15]. The amount of press hardened steels in vehicles as structural components has increased in recent years. For example, the new generation of Volvo cars has introduced press hardened steels up to $38 \%$ of the total body weight, [11]. Al-Si coating on boron steels is commonly

Liang Deng

liang.deng@1tu.se

1 Division of Mechanics of Solid Materials, Department of Engineering Sciences and Mathematics, Lulea University of Technology, 97187 Luleå, Sweden

2 Division of Machine Elements, Department of Engineering Sciences and Mathematics, Lulea University of Technology, 97187 Luleå, Sweden employed in the press hardening for oxidation prevention of workpieces. This coating is of interest as it does not severely impair the weldability and paintability, as reported by [24].

Production of Al-Si coated press hardened components often results in occurrence of severe adhesive wear during the tool-workpiece interaction due to the harsh contact conditions, such as high temperatures, cyclic loadings and complex interaction between oxides and coatings. Galling, i.e. build-up of transferred material on the tool surface causes damage to the surface of the produced components in the form of scratches and it can even lead to changes in their shape, thus affecting the trimming quality.

In order to understand the galling mechanism, researches first put attention on the galling initiation. Pelcastre et al. [17] reported observation on a hot forming tool against $\mathrm{Al}-\mathrm{Si}$ boron steels that galling mainly occurs in curved surfaces. Through higher magnification images of the transferred material, the built-up material is observed as the structure consisting of compacted adherent coating and tool material fragments. Tian et al. [25] identified that the adhesive wear as a predominant wear mechanism occurred in a laboratory test above $600{ }^{\circ} \mathrm{C}$. The analysis of the galling evolution was reported by Pelcastre et al. [18], and it was suggested that there are two main mechanisms that lead to the 
development of galling: direct adhesion and accumulation of compacted wear particles. Besides the threshold temperature, a minor stain of the Al-Si-coated blank is correlated to the galling initiation because it indicates the breakout of the coating during the deformation, Wieland and Merklein [26].

Looking at the reported results in the open literature, it is clear that the accumulation of the wear particles on to the tool surface is a predominant source for the development of galling. However, the galling behaviour is a tribo-system response involving lots of factors such as material combinations, test conditions and set-ups of the tests result in different observations. Furthermore, the galling evolution in extended sliding has not been studied. Whether the galling evolution experiences a running-in, stable stage and eventually catastrophic failure is not studied yet.

High cost and difficulties in in situ measurement restrict the study of galling in press hardening processes. A laboratory test simulating the press hardening processes is an alternative method to simulate and to study tribological behaviour of the materials of interest. Some simplified laboratory tests at different levels have been employed by researchers. A pin-on-disk test configuration has been widely used to study friction behaviour for different material combinations (such as in the works by Ghiotti et al. [7] and Mozgovoy et al. [13]). The disk is heated to high temperatures and the pin slides against it with a specific load. In this type of configuration, the pin surface is always in contact repeatedly on the same track of the counter disk specimen; this is different from the press hardening process as in the real application a fresh workpiece surface is in contact with the non-changing die surface for each formed component. In order to better simulate sliding during the forming operation, a strip-drawing type test has been developed by researchers, cf. [4, 25, 27, 28]. Typically, a steel sheet strip is heated to the test temperature and drawn across the loaded tool specimen surfaces with a certain velocity. The tool steel specimen is loaded against the strip during the sliding process. Based on this type of experimental equipment, Tian et al. [25] pointed out that $600{ }^{\circ} \mathrm{C}$ is the critical temperature for initiating severe adhesion, where grooving (abrasive wear) is the main observation at temperature from room temperature to $500{ }^{\circ} \mathrm{C}$. At higher temperature above $600{ }^{\circ} \mathrm{C}$, friction coefficients increase due to the combined effect of the severe adhesion. Yanagida and Azushima [27] observed a similar temperature effect on the friction coefficient. In their study, a longer sliding distance was used for the same steel strip; in this case, the friction coefficient increased with the increasing sliding distance due to an increase in the tool steel temperature [28]. However, the strips are typically heated in a furnace prior to the tests, which means that the actual temperature of the strip decreases during the sliding process. Thus, the different changes in the sample temperature increase the uncertainty in the evaluation of the tribological behaviour. Compared to the aforementioned test, a complex test corresponding to a deep-drawing test has been employed by Groche and Nitzsche [8], which is used to determine the friction coefficient and to evaluate the effect of process parameters, coatings and tool surface engineering on material transfer. However, the result from this dedicated test is valid in narrow ranges of test conditions.

In the present study, a tribological test reproducing the sliding conditions during press hardening is used to study the galling evolution during extended sliding. The test conditions are based on the finite element (FE) simulation of a press hardening experiment and have been used during the tests to mimic the press hardening conditions. In order to understand the galling evolution, frictional behaviour is studied. The galling measurement is performed by a 3D optical surface profilometer through estimating the volumetric change of material build-up on tool specimen surface. The galling volume leading to the shape change of tool provides a base to study how the galling negatively affects the contact conditions in the press hardening. A numerical model of the tribological test is used to analyse localized contact conditions at the tool-workpiece interface. A simple galling model is applied in the FE-simulation to demonstrate the possibility of the galling prediction. The predicted galling height is used to update the geometry of the specimen, which results in the pressure fluctuation.

\section{Methodology}

\subsection{Tribological Test}

The picture and schematics of the tribological test are presented in Fig. 1 and this test has been used to study the tribological behaviours subjected to contact conditions prevalent in press hardening.

The boron steel strip was clamped by hydraulically actuated clamping jaws in the main frame. The sheet strip was heated by the Joule effect, passing a current through the strip. Since the heating method in the tribological test was quicker compared to the heating obtained with the industrial furnaces used in a production line, a stepwise heating process was employed for the strip. This was done with the purpose of obtaining similar microstructures of the Al-Si coated boron steel as that of the industrial application. The microstructures of the coating in real productions was described by Pelcastre et al. [19]. In the present heating process, the heated strip was maintained at 600,700 and $900{ }^{\circ} \mathrm{C}$ for $4 \mathrm{~min}, 2 \mathrm{~min}$ and $30 \mathrm{~s}$, respectively. After that, the steel strip was cooled in air down to the test temperature for $30 \mathrm{~s}$ before the onset of sliding. The strip temperature in the heating process was calibrated using a pyrometer. Since the pin was affected by the heat radiation during the strip heating process, a type-K thermocouple was welded 


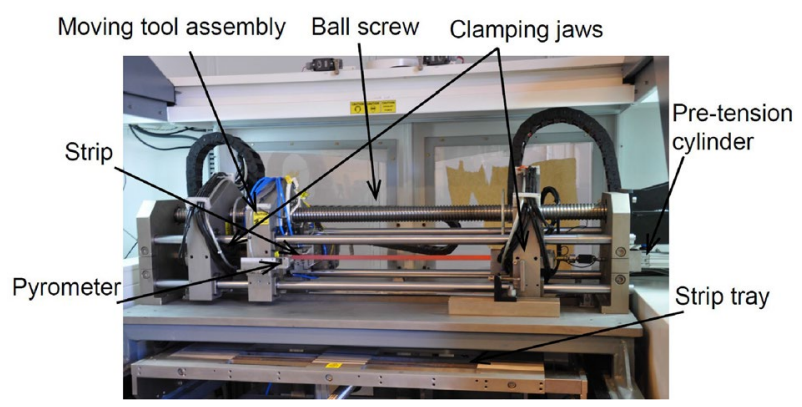

(a)

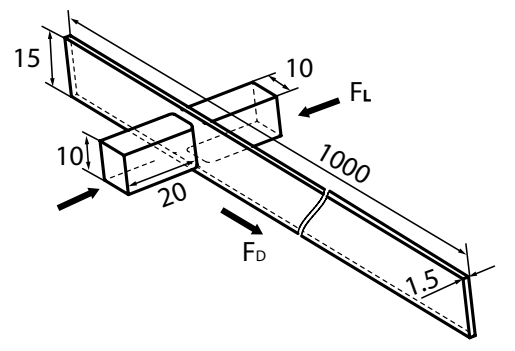

(b)

Fig. 1 a Main features of the tribological test machine; b simplified illustration of the sliding process in the tribological test without tool steel pin holders, all dimensions in $\mathrm{mm}$

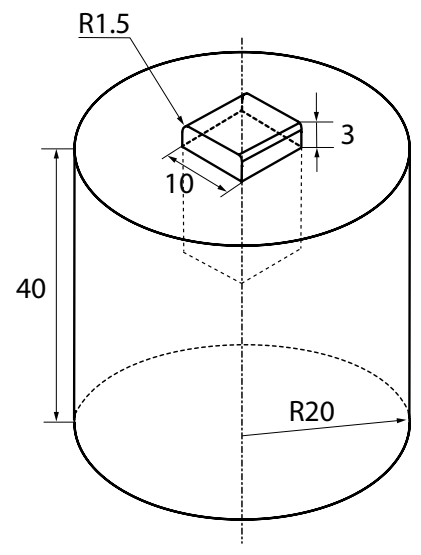

Fig. 2 Illustration of the pin in the holder, all dimensions in $\mathrm{mm}$

at the pin lateral surface edge to monitor the tool temperature during the tests. A pretension was applied to the strip using a pneumatic cylinder to prevent deformation of the strip during heating and sliding. In order to minimize the accumulation of loose wear debris, the steel strip was mounted vertically in this set-up. Two tool pin specimens were loaded against the strip (one from each side) using a pneumatic bellow. Once the load was applied, sliding was carried out along the length of the strip by means of a ball screw driven by an electric motor. In the tool assembly, a holder accommodated a tool steel pin as shown in Fig. 2. The test pin was designed with a flat surface and the leading and trailing edges of the pin surface had a radius of $1.5 \mathrm{~mm}$. The flat surface provided a stable accommodation for the development of galling. The normal force and tangential force during the sliding process were measured by strain gauge force transducers and the friction coefficient was calculated according to following equation:

$\mu=\frac{F_{\mathrm{D}}-F_{\mathrm{P}}}{2 F_{\mathrm{L}}}$,

where $F_{\mathrm{D}}$ represents the drawing force; $F_{\mathrm{P}}$ denotes the pretension force, and $F_{\mathrm{L}}$ denotes the load applied on the pin, as shown in Fig. 1 b.

In the present test, the pin was made of hardened tool steel (QRO 90) and the boron steel strips were cut from the asreceived hot-dip aluminized sheets (USIBOR 1500). Table 1 presents the chemical composition. Both of the specimen materials are typically used in the press hardening processes. The tool steel pin surface was ground to a roughness in the range of $0.35-0.40 \mu \mathrm{m}(\mathrm{Sa})$, which is a typical value encountered in forming dies for press hardening. The roughness the Al-Si-coated boron steel strip was approximately $3.6 \mu \mathrm{m}(\mathrm{Ra})$ after the heating process.

Table 2 shows the test conditions used for the tribological test, which were based on simulation results of the contact conditions in a press hardening experiment, as reported in the previous work done by Deng et al. [4]. The press hardening experiment is a prototype of typical crash forming processes performed in a real production line and corresponding FEsimulations present the contact conditions occurring in the stamping tools. The test temperatures from 600 to $750{ }^{\circ} \mathrm{C}$ applied in the tribological test covered the range of the temperature occurring in the workpiece during the drawing process, where galling is expected as mentioned by Tian et al. [25]. The test pressures were lower than the mean pressure in the press hardening experiment (as seen in [4]) to prevent fracture of the strip due to a combined effect of the softening at high temperature and the high adhesive forces experienced during the experiment. Furthermore, a relatively small pressure employed in a stable tribo-test is reasonable because high
Table 1 Chemical composition of the specimens in the tribological test in wt\% (Fe makes up the balance) and initial hardness

\begin{tabular}{llllllllll}
\hline Material & $\mathrm{C}$ & $\mathrm{Si}$ & $\mathrm{Mn}$ & $\mathrm{P}$ & $\mathrm{Cr}$ & $\mathrm{Mo}$ & $\mathrm{V}$ & $\mathrm{B}$ & $\mathrm{Hv}_{0.5}$ \\
\hline USIBOR 1500 & 0.23 & 0.29 & 1.25 & 0.013 & 0.211 & - & - & 0.003 & - \\
QRO 90 & 0.38 & 0.30 & 0.75 & - & 2.6 & 2.25 & 0.9 & - & $540 \pm 40$ \\
\hline
\end{tabular}


Table 2 Experimental parameters in the tribological test

\begin{tabular}{ll}
\hline Test parameters & Value \\
\hline Temperature in strip $\left({ }^{\circ} \mathrm{C}\right)$ & $600,700,750$ \\
Pressure $(\mathrm{MPa})$ & $5,10,15$ \\
Velocity $(\mathrm{m} / \mathrm{s})$ & 0.1 \\
Sliding distance per strip $(\mathrm{mm})$ & $50,200,400$ \\
\hline
\end{tabular}

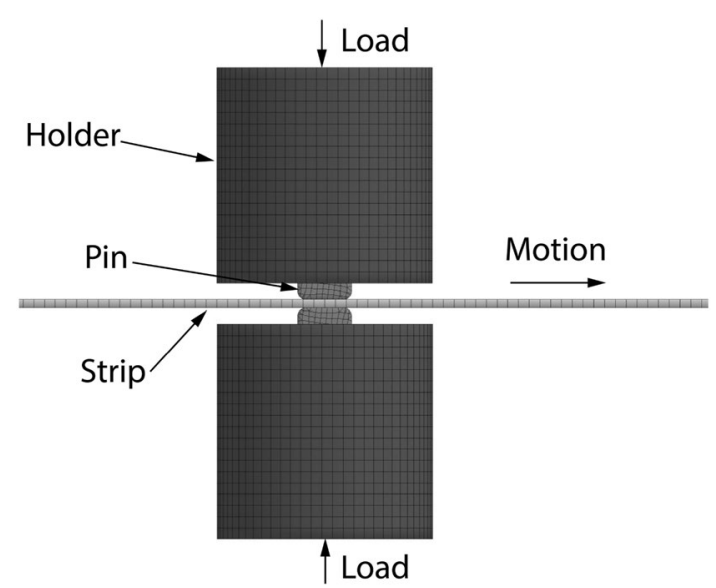

Fig. 3 Set-up of the FE-simulation of the tribological test, only the partial strip is shown

contact pressure exists in the press hardening experiment but oscillates in time and space. One constant sliding velocity was employed in the tribological test because [14] pointed that the influence of velocity on the wear behaviour is small. In the FE-simulation of the press hardening experiment, the maximum sliding distance per stroke is about $60 \mathrm{~mm}$, cf. [4]. The sliding distance per strip in the tribological test was $50 \mathrm{~mm}$ and new strips were tested until severe galling occurred. When mild galling was observed in the tests, a longer stroke length $(200 \mathrm{~mm})$ was used in order to accelerate the development of galling. In some cases, even under these conditions, severe galling was not observed and a steady state was developed (stable coefficient of friction and steady growth of galling). In these cases, a maximum total sliding distance of $2200 \mathrm{~mm}$ was used. The total sliding distance on the same pin specimen was fulfilled by an automated pick and place mechanism feeding in new strips and removing the worn strips, where the same heating process was applied on the new strip.

\subsection{FE-Simulation of the Tribological Test}

Since the real contact conditions at the interface were unknown, a numerical model of the tribological test was developed with LS-Dyna to analyse the localized contact conditions as shown in Fig. 3. The element size in the interface was $0.2 \mathrm{~mm}$ but it increased towards the bulk to save computational time. The material model used for the boron steel strip was a thermo-elastic-plastic constitutive model developed by Åkerström et al. [3] and Åkerström and Oldenburg [1], which was implemented in LS-Dyna as 244 material model. The chemical constituents used in the material model of the boron steel strip were identical to Table 1. The stress-strain relation of the boron steel strip for the different phases was extracted from Åkerström et al. [2] and Sjömström [23] for austenite, Rudiono and Tomota [21] and Huang et al. [10] for ferrite, Sjömström [23], Rudiono and Tomota [21], and Nakkalil et al. [16] for perlite, Rudiono and Tomota [21] and Petit-Grostabussiat et al. [20] for bainite, Eriksson et al. [5] for martensite. The thermal data, such as expansion coefficients for different phases and the latent heat for the decomposition of austenite, were extracted from [12]. This material model with the chosen material parameters has been validated by a press hardening test in terms of thickness of formed parts and forming forces by Åkerström and Oldenburg [1]. The pins were considered as elastic bodies while the holders were rigid bodies in the present numerical model. The friction coefficient used in the FE-simulation was the averaged value extracted from the tribological tests. The heat transfer coefficient used for the interface was calculated by a pressure dependent function as depicted in Eq. 2 [6]. This equation was a fitting function based on experiments. In the present work, the nominal contact pressure was used to estimate the heat transfer coefficient. The heat capacity and thermal conductivity of the pin were assumed to be $460 \mathrm{~J} / \mathrm{kg}{ }^{\circ} \mathrm{C}$ and $33 \mathrm{~W} / \mathrm{m}{ }^{\circ} \mathrm{C}$, respectively.

$\mathrm{HTC}=53.94 \times P+1271.3$,

where HTC is the heat transfer coefficient in $\left(\mathrm{W} / \mathrm{m}^{2} \mathrm{~K}\right)$ and $P$ is the pressure in (MPa).

\section{Results and Discussion}

\subsection{Frictional Behaviour}

The increase of temperature at the pin surface was obtained by the FE-simulation, where the calculated temperature was validated by a thermocouple attached to Position 1 , as seen in Fig. 4. The temperature in the pin rose to $107^{\circ} \mathrm{C}$ before the onset of sliding, which was attributed to radiation during the heating process and to heat transfer during the loading process. The central temperature in the pin top surface (Position 2) increased to $198^{\circ} \mathrm{C}$ after a sliding distance of $50 \mathrm{~mm}$ due to the combination of heat transfer and friction energy accumulation.

An uneven of pressure profile towards the leading edge resulted in accumulation of wear particles at the centre of the leading edge of the pin after a certain distance of sliding, 


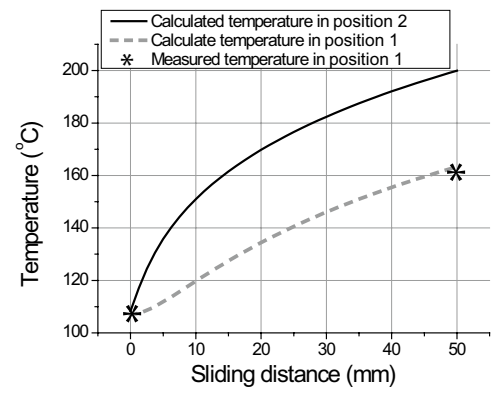

(a)

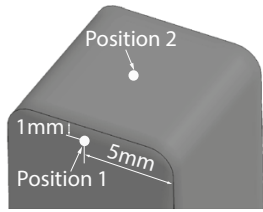

(b)
Fig. 4 a Temperature measurement of the pin during the sliding process of $50 \mathrm{~mm}$; test conditions: $750{ }^{\circ} \mathrm{C}, 10 \mathrm{MPa}$; $\mathbf{b}$ illustration of the temperature measurements in the pin

as seen in Fig. 5. The tribo-system became highly unstable when the transferred material accumulated at the leading edge at a certain level.

Table 3 shows the total sliding distances for each of the tested conditions. The severe galling occurrence at the leading edge was identified by the sudden increase in the friction coefficient, as shown in Fig. 6 for the experiment done at $700{ }^{\circ} \mathrm{C}$.

The short sliding distance performed in the test at $600{ }^{\circ} \mathrm{C}$ with $15 \mathrm{MPa}$ was due to the occurrence of severe abrasive wear, which caused a burnishing effect on the edge of the tool pins. Under these conditions, the coefficient of friction was relatively stable (shown in Fig. 6) and the transferred material was negligible, as seen in Fig. 7. This was attributed to the higher hardness of the Al-Si coating at a lower test temperature coupled with the concentrated pressure at the leading edge. The employed stepwise heating history resulted in 4 layers of the coating microstructure which is similar to that described by Pelcastre et al. [19]. Hardell et al. [9] pointed out that the outer layer of the heat-treated Al-Si coating has a high hardness (about $870 \mathrm{HV}$ ), which led to the significant
Table 3 Total sliding distance $(\mathrm{mm})$ in the tribological test

\begin{tabular}{llll}
\hline Test conditions $\left({ }^{\circ} \mathrm{C}\right)$ & $5 \mathrm{MPa}$ & $10 \mathrm{MPa}$ & $15 \mathrm{MPa}$ \\
\hline 750 & 600 & 400 & 50 \\
700 & 1800 & 2200 & 200 \\
600 & 2200 & 2200 & 200 \\
\hline
\end{tabular}

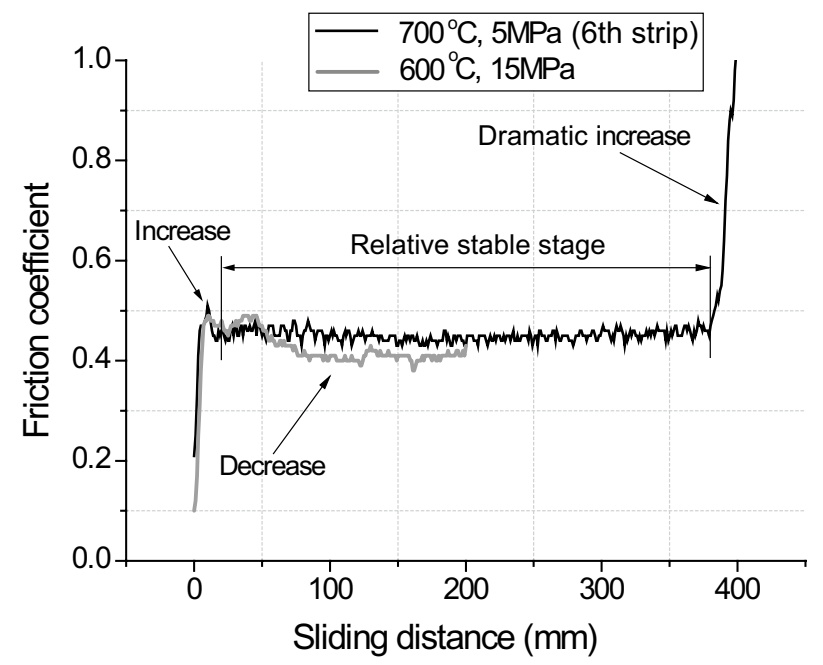

Fig. 6 Frictional coefficients during the sliding process

abrasion of the tool pin surface which has a hardness of about $550 \mathrm{HV}$. Figure 8 shows the microstructure of the coating obtained from the tribometer test. The structure of the coating correlated to the work done by Hardell et al. [9] and Pelcastre et al. [19]. A detailed analysis of the microstructure of the coating was not in the scope of the present work.

As illustrated by a typical friction curve in the test at $700{ }^{\circ} \mathrm{C}$ with $5 \mathrm{MPa}$ in Fig. 6, an increase in friction coefficient at the beginning was observed in all of tests. This increase was attributed to a combined effect of the

Fig. 5 Illustration of the results of the test at $750{ }^{\circ} \mathrm{C}$ with $10 \mathrm{MPa}$ : a uneven pressure distribution in the leading edge of the pin obtained from the FE-simulation; b severe galling occurring in the pin leading edge; an arrow indicates the sliding direction of the steel strip

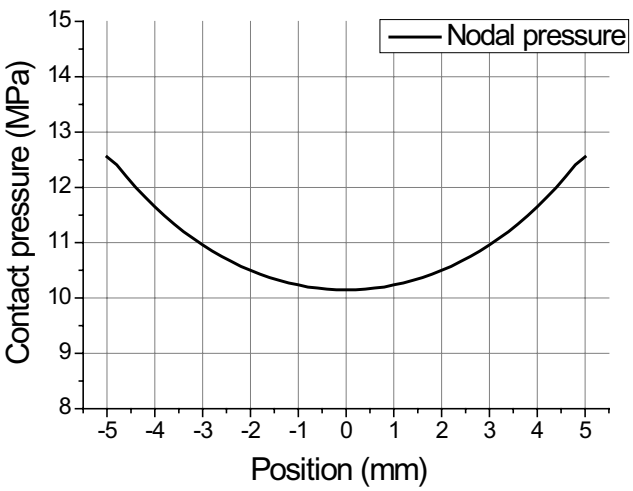

(a)

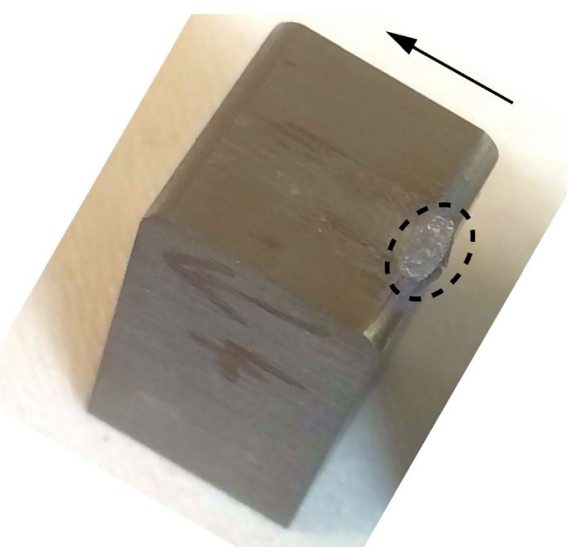

(b) 


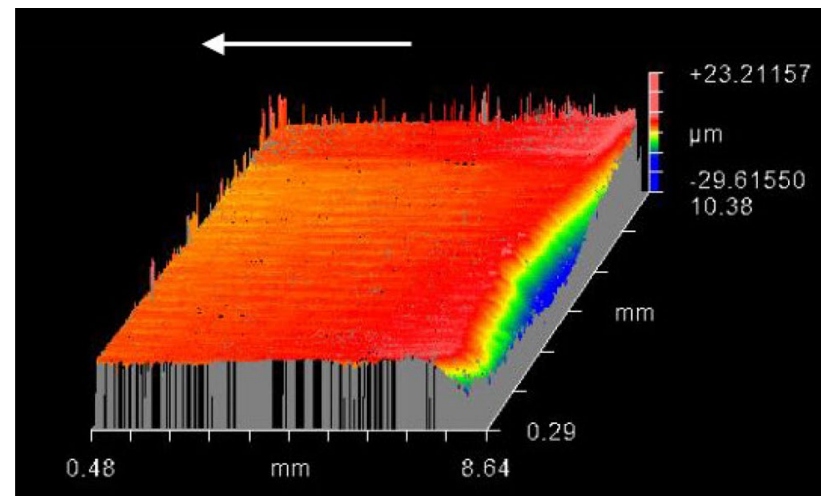

Fig. 7 Worn pin surface at $600{ }^{\circ} \mathrm{C}$ with $15 \mathrm{MPa}$ obtained by a 3D surface profilometer, an arrow indicates the sliding direction of the boron steel strip

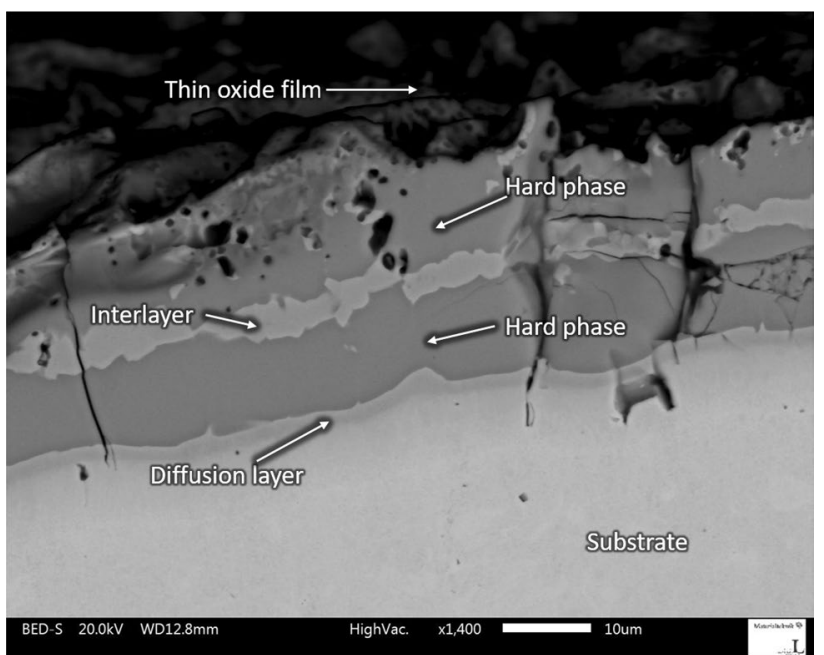

Fig. 8 Structure of the Al-Si coating after the stepwise heating process

acceleration of the tool assembly and the static friction between the pin specimens and the strip after applying the load. This was followed by a decrease of the coefficient of friction due to a running-in effect caused by the occurrence of abrasive wear and/or the development of a transfer layer. As the sliding progressed, the transferred layer becomes a load bearing surface which initially results in a moderated friction coefficient. Figure 9 presents the average friction coefficients during the extended sliding, where the mean values were collected from the stable frictional stages of each stroke. It is important to note that initial two strokes at $600{ }^{\circ} \mathrm{C}$ with $5 \mathrm{MPa}$ were not taken into account because the friction coefficient highly fluctuated due to instabilities in the contact. This unstable contact may attribute to the running-in effect. A clear trend towards a decreasing friction coefficient was only observed in the test at $600{ }^{\circ} \mathrm{C}$ with

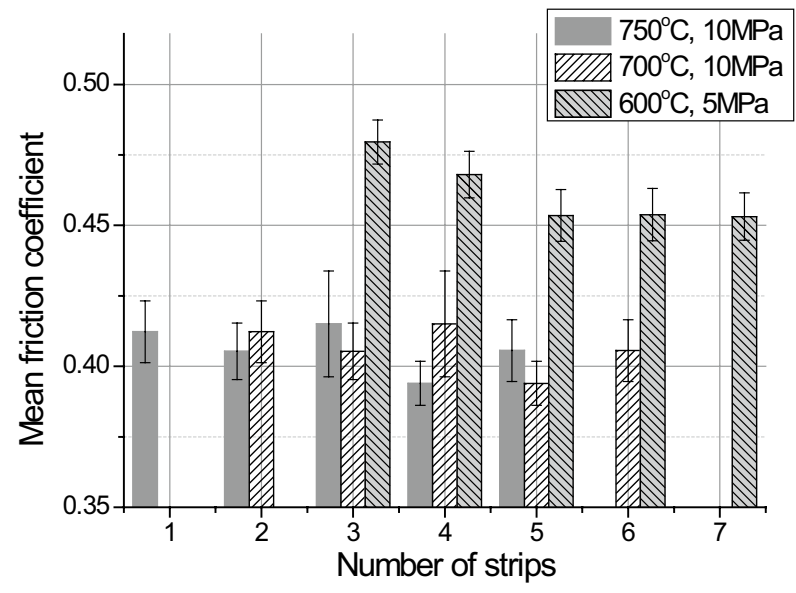

Fig. 9 Progressive friction coefficients at different test conditions

$5 \mathrm{MPa}$, which was attributed to the running-in phase and a polishing effect on the tool surface by the harder $\mathrm{Al}-\mathrm{Si}$ coated boron steel. The polishing effect led to a decrease in pin surface roughness near the leading edge as presented in Fig. 10. It is important to note that the coefficient of friction was higher at $600{ }^{\circ} \mathrm{C}$ but no significant material transfer or embedded wear debris was observed after the tribological tests, which suggests that the coefficient of friction is mostly controlled by the abrasive behaviour. On the other hand, the adhesive wear became significant at higher temperatures and controlled the friction response at 750 and $700{ }^{\circ} \mathrm{C}$.

Figure 11 shows mean friction coefficients after the total sliding in different test conditions. At $600{ }^{\circ} \mathrm{C}$, the friction coefficient decreased when the contact pressure was increased from 5 to $10 \mathrm{MPa}$. This can be explained by the development of a rapid running-in caused by a combined effect of plastic deformation in the contact due to a higher load and the occurrence of abrasive wear, which resulted in a conformal contact early in the sliding process.

At $700{ }^{\circ} \mathrm{C}$, the friction coefficient initially decreased going from 5 to $10 \mathrm{MPa}$. Transfer layers were observed at this temperature (see Fig. 12), this is likely an indication that at $10 \mathrm{MPa}$, the developed transfer layers were stable and bore by the load, and thus the ploughing component of friction was reduced and mainly the adhesive forces contributed to the coefficient of friction. The reduced friction coefficients with the increased loads were also reported by Yanagida et al. [28]. In their study, they attributed this reduction to the small ratio between the contact pressure to the yield stress of the specimen. When the contact pressure was increased to $15 \mathrm{MPa}$, the coefficient of friction was higher as a result of the rapid development of galling at the leading edge.

At $750{ }^{\circ} \mathrm{C}$, friction coefficient increased significantly when the contact pressure was increased from 5 to $10 \mathrm{MPa}$, but only a slight increase was observed when the contact pressure was $15 \mathrm{MPa}$. At $10 \mathrm{MPa}$, a stable behaviour of the 
Fig. 10 Roughness measurement in the pin used in the test at $600{ }^{\circ} \mathrm{C}$ with $5 \mathrm{MPa}$; an arrow indicates the sliding direction of the steel strip: a illustration of the measured position (dash line); $\mathbf{b}$ measured roughness

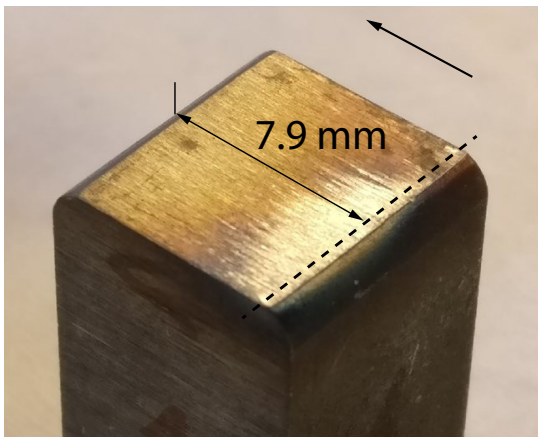

(a)

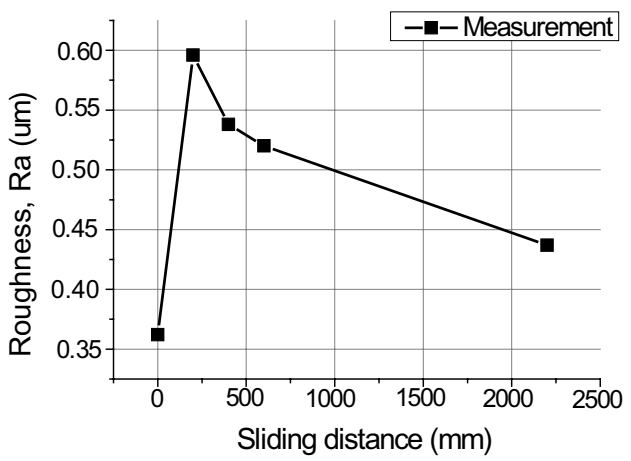

(b)

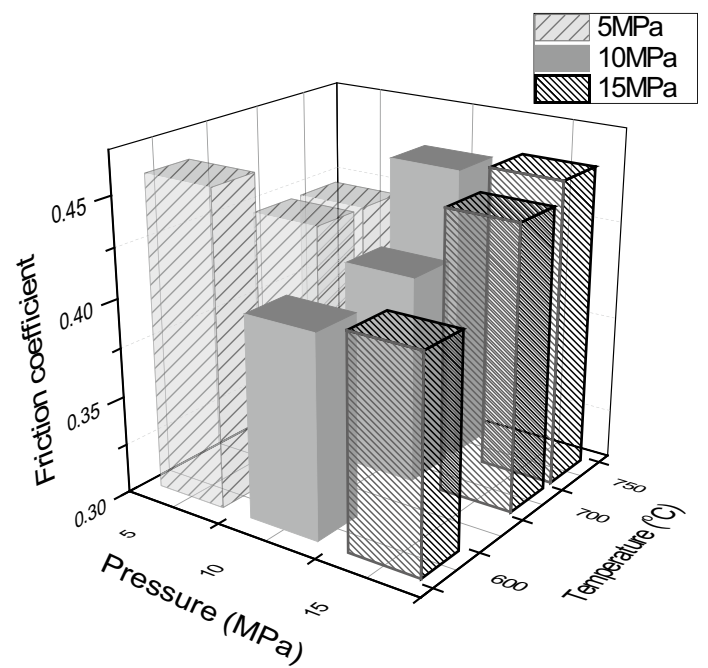

Fig. 11 Mean friction coefficients measured by overall strips in each test condition combination coefficient of friction was observed, which again, was an indicative of a relative stability of the transfer layer (galled material). However, the transfer layer continued to grow at the leading edge at a rapid rate, thus resulting in early failure due to severe galling (about $250 \mathrm{~mm}$ total sliding). This has also been discussed by Schwingenschlögl et al. [22]; more adhesion occurred at a higher load in conjunction with the enhanced sintering effect at higher temperatures. It is important to note that the coefficient of friction reported in this figure corresponds to the most stable part of the friction curves and the curve for $15 \mathrm{MPa}$ contact pressure was relatively stable only for about $2 \mathrm{~mm}$ of sliding distance.

\subsection{Galling Behaviour}

In order to quantitatively measure the galling, the material built-up on the pin surface was measured. After each stroke of sliding, the worn pin was measured by a 3D optical

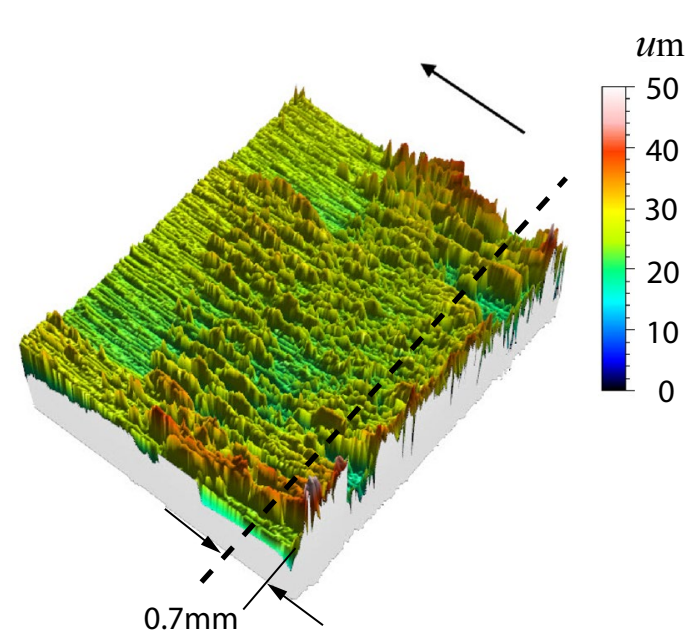

(a)

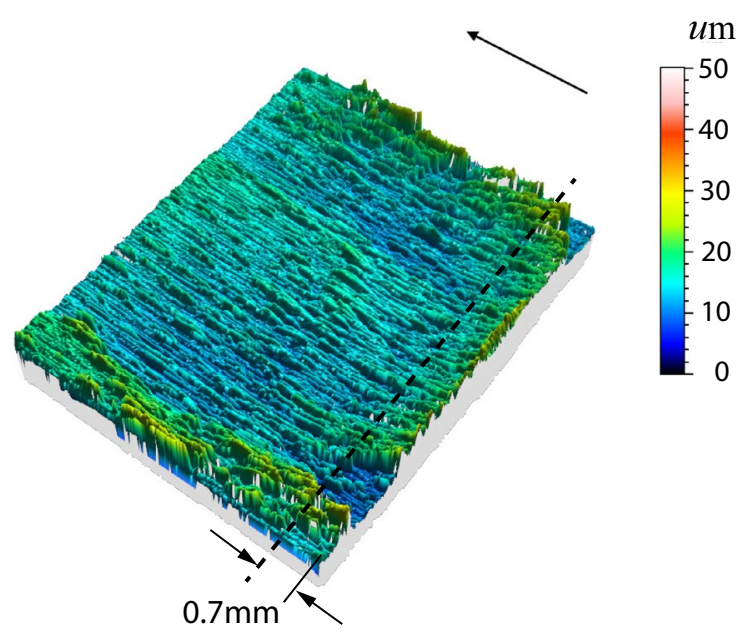

(b)

Fig. 12 Optical observation in worn pin surface after $1400 \mathrm{~mm}$ : a at 700 with $5 \mathrm{MPa}, \mathbf{b}$ at 700 with $10 \mathrm{MPa}$, upper arrows indicate the sliding direction of the strip and dash lines indicate the position of roughness measurement 
surface profilometer, ZYGO NewView 7300, using $2 \times 2.75$ optical magnification. The galling volume was estimated by the commercial software, Mountains Map. A reference plane for the volume estimation was defined by the least square hight of a chosen unworn area. Since the surface of the pin at a microscopic level was filled with asperities, grooves and steps due to grinding, uncertainties such as the choice of the unworn area, slant and waviness of the pin surface exist in the galling measurement, nevertheless, it is a good indication of the existing trends observed in this work. Figure 13a presents growth rate of galling derived from volume gains, normal force and the total sliding distance in the different test conditions, Eq. 3. The measurement of volume gains excluded the severe galling accumulating in the leading edge of the pin.

$g=\frac{V}{F S}$,

where $g$ is the growth rate of galling in $\left(\mathrm{m}^{3} / \mathrm{N} \mathrm{m}^{-1}\right) ; V$ is the gained material volume in $\left(\mathrm{m}^{3}\right) ; F$ is the normal load in $(\mathrm{N})$ and $s$ is the sliding distance in $(\mathrm{m})$.

In generally, the variational trends of the growth rate in all test temperatures were due to the stability of the transferred material. At $10 \mathrm{MPa}$, the load was sufficient to sinter/compact a stable layer and the growth of the layer was relatively slow. However, the growth rate increased with temperature as the sintering effect as well as the adhesion increased. At $15 \mathrm{MPa}$, the significant sintering effect resulted in a gradual increase of galling growth rate with temperature. At $5 \mathrm{MPa}$, the transferred material was not compacted as much as it was at higher loads. Figure 12 presents the compacted profile of the galling at $10 \mathrm{MPa}$ compared to that at $5 \mathrm{MPa}$, where the roughness values (Ra) at the measured positions were $1.48 \mu \mathrm{m}$ in the test with $10 \mathrm{MPa}, 2.18 \mu \mathrm{m}$ in the test with $5 \mathrm{MPa}$.

The highest growth rate of galling occurred at $750{ }^{\circ} \mathrm{C}$ with $10 \mathrm{MPa}$ because galling continuously increased during sliding as seen in Fig. 13b. The volume gain presented a decreasing tendency in the test at $750{ }^{\circ} \mathrm{C}$ with $5 \mathrm{MPa}$, indicating that the built-up material may break off during the early stages of sliding before the transferred layer has fully sintered. Based on Fig. 13b-d, sharp increase in volume gains generally occurred in the beginning, thus indicating a running-in stage, followed by a mild galling development stage and then the volume gains ended up with a dramatic increase when severe galling occurred at the leading edge of the contact. Figure $13 \mathrm{c}$ shows the volume change at $700{ }^{\circ} \mathrm{C}$, where the lower pressure led to slightly more material gain. Figure 13d illustrates an decrease in the volume gain in the test at $600{ }^{\circ} \mathrm{C}$ with $10 \mathrm{MPa}$ while the volume change in the test at $600{ }^{\circ} \mathrm{C}$ with $5 \mathrm{MPa}$ from the sliding 600 to $2200 \mathrm{~mm}$ was small. The small variation of the volume with sliding for the tests at $600{ }^{\circ} \mathrm{C}$ was caused by the dominance of the

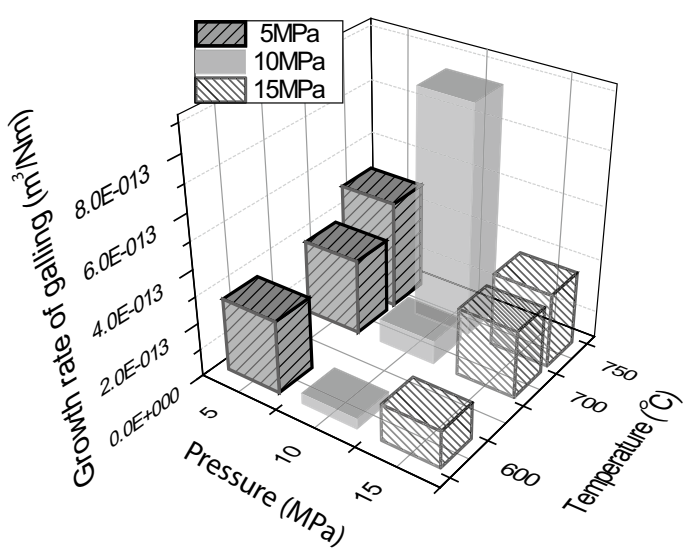

(a)

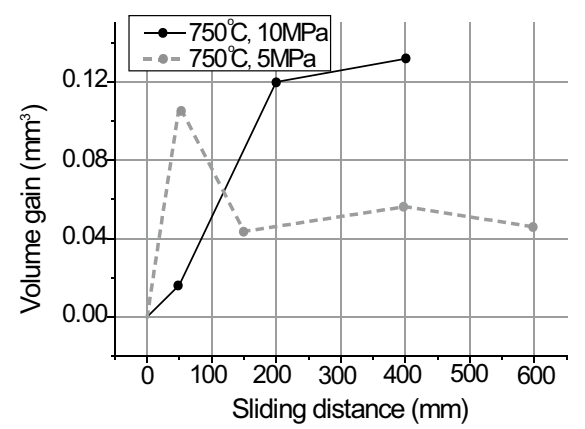

(b)

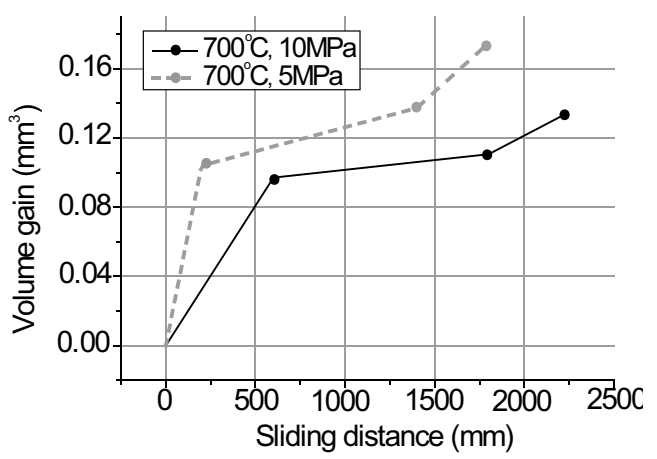

(c)

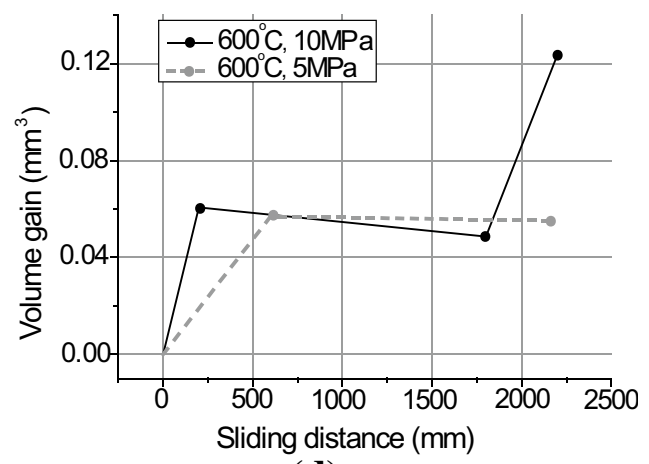

(d)

Fig. 13 Quantitative wear measurement in different test conditions 
abrasive wear behaviour, even if some material transfer was observed, this was minimal. However, at $10 \mathrm{MPa}$, galling was more significant at the leading edge, particularly towards the end of the test, which is reflected in the volume gain observed in Fig. 13d. The growth rate illustrated the galling severities for the different conditions. However, it has to be noted that severe galling occurred very early in the tests done at $15 \mathrm{MPa}$, and thus the galling evolution was not studied by replaced strips.

\subsection{Galling Simulation}

Based on the galling growth rate obtained from the tribological tests, a simple galling model was applied in the numerical model of the tribological test, as seen in Eq. 4. This galling equation was derived from Archard model in which $A$ is the area subjected to galling. There were two assumptions relied on. Firstly, the build-up material formed a cubic shape. Secondly, the final galling height was linearly extrapolated by total sliding distance. The galling simulation was used to demonstrate the feasibility of the galling predictive model.

$h=\frac{V}{A}=g \times \frac{F}{A} \times s=g \times P \times s$,

where $h$ is the galling height in [m]; $A$ is the nominal contact area in $\left(\mathrm{m}^{2}\right) ; P$ is the pressure in $[\mathrm{Pa}] ; g$ is the galling growth rate in $\left(\mathrm{m}^{3} \mathrm{~N} \mathrm{~m}^{-1}\right)$ and $s$ is the sliding distance in [m]. The proportional relation between the galling height and the process parameters referring to the pressure and the sliding distance was assumed in the present work, which was base Archard wear model. Figure 13a presents the temperature and pressure dependent galling growth rates, which worked as an adjuster for the proportional relation between the galling height and the process parameters. Since the apparently non-linear relation between the galling and the sliding distance as shown in Fig. 13b-d, the galling growth rate used in the galling model was obtained without the sliding on last strip that typically involved severe galling accumulating in the front edge of the pin.

According to the galling result of the tribological test, the galling developed abruptly at $750{ }^{\circ} \mathrm{C}$, which was caused by the high growth rate of galling and the consequently severe wear particles accumulating in the leading edge after short distances. However, the severe wear particle accumulation was not considered in the present galling simulation. On the other hand, $600{ }^{\circ} \mathrm{C}$ resulted in reduced galling due to abrasive wear and ploughing effect, which was not a typical galling process predicted by the current galling simulation. Currently, the galling simulation was demonstrated by use of a intermediate growth rate approaching for the sliding process at $700{ }^{\circ} \mathrm{C}$ with $10 \mathrm{MPa}$. The predicted galling distribution after $1800 \mathrm{~mm}$ of sliding is presented in Fig. 14a. According to Fig. 14b, the transferred material radially distributed and concentrated in the front and both side edges in the worn pin surface. The predicted galling distribution showed a good accordance with the surface observations of the pin at the test after $1800 \mathrm{~mm}$, see Fig. 14. Since the real galling significantly concentrated in the high-pressure area (surrounding edge of the pin), the predicted galling height was underestimated because the galling height was calibrated by the galling volume dividing by the nominal contact area of the pin surface. The predicted galling height equalled to the mean height of the measured galling height. A factor $\alpha$ was used to scale up the predicted value so as to match the maximum measured height of galling, as seen in Equation 5. The scaled galling height in the numerical model aimed in studying the influence of the actual galling height on product quality.

$h=g \times \frac{F}{\alpha A} \times s=\frac{1}{\alpha} \times g \times P \times s$.

Table 4 presents the results of the galling simulation with the $\alpha$. The identically maximum height of the galling was obtained by the simulation with $\alpha$ as 0.1 . However, the

Fig. 14 Comparison of the galling in the pin surface at $700{ }^{\circ} \mathrm{C}$ with $10 \mathrm{MPa}$ : a galling simulation, b surface observation after $1800 \mathrm{~mm}$; arrows indicate the sliding direction of the steel strip

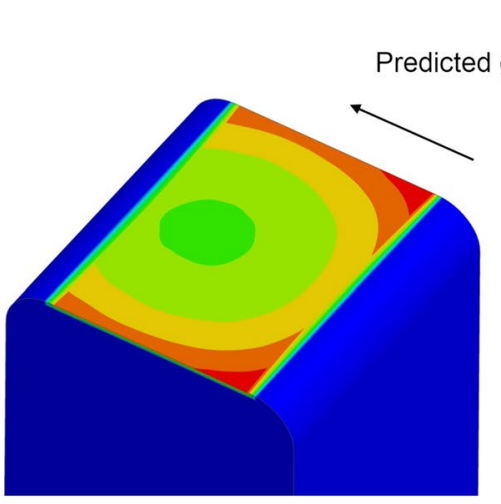

(a)

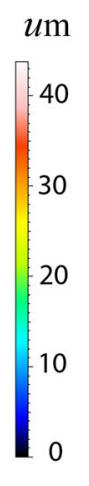

(b) 
Table 4 Galling results after the sliding of $1800 \mathrm{~mm}$ at $700{ }^{\circ} \mathrm{C}$ with $10 \mathrm{MPa}$

\begin{tabular}{lcl}
\hline Parameter & Max. height $(\mu \mathrm{m})$ & Volume $\left(\mathrm{mm}^{3}\right)$ \\
\hline Measurements & 21.5 & 0.11 \\
Prediction with $\alpha=1$ & 2.15 & 0.085 \\
Prediction with $\alpha=0.1$ & 21.5 & 1.04 \\
\hline
\end{tabular}

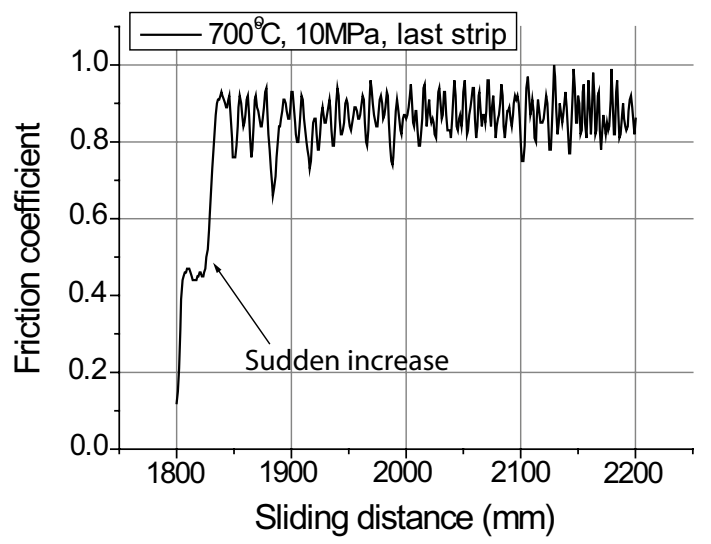

Fig. 15 Friction coefficient after $1800 \mathrm{~mm}$ in the test at $700{ }^{\circ} \mathrm{C}$ with $10 \mathrm{MPa}$

calculated galling volume was overestimated since the calculated galling volume was linearly enlarged up by the $\alpha$. The scaled up galling height can be used to study the galling effect on the contact conditions; however, the overestimated galling volume as calculated confirmed that the galling evolution had a strong non-linear relation with the pressure as well as the sliding distance.

The severe galling drastically developed in the leading edge after the sliding distance of $1800 \mathrm{~mm}$ as indicated by a sudden increase in friction coefficients, as seen in Fig. 15. This may attribute to the effect of the worn surface of the pin. The early built-up material may change the surface shape of the pin surface, which made wear debris drastically piled up in the leading during the continuous sliding. When the material accumulating in the leading edge until a certain amount, the tribo-system became unstable and the consequent increase in friction coefficient was obtained. The geometry updated pin surface based on predicted galling height after $1800 \mathrm{~mm}$ sliding was applied in the simulations so as to study the influence of galling on the contact conditions.

The pressure in the central leading edge of the updated pin is presented in Fig. 16a. An abrupt increase in the pressure in the beginning of the sliding was obtained in the pin leading edge with $\alpha=0.1$. As seen in Fig. 16a, small oscillations in the pin displacement in the loading direction during the sliding was obtained in numerical models. The pressure fluctuation in the worn pin was caused by the vibration of the pin due to the uneven pin surface, see Fig. 16b. The fluctuations in the pressure and displacement in the numerical model using the worn pin were relevant to the severe galling accumulation after the sliding of $2200 \mathrm{~mm}$.

\section{Conclusions}

The present work outlined a tribological test for galling evaluation in press hardening conditions. A numerical model of the test has been developed in order to understand galling behaviour in terms of the contact conditions at the tool-workpiece interface. The concentrated pressure in the leading edge of specimens led to severe galling in the test, which restricted the extended sliding. In the friction results, the effect of the pressure was small and the most significant changes in friction coefficients were related to the test temperatures. In the galling evaluation, the test temperature was an important factor in terms of the galling severity. At $750{ }^{\circ} \mathrm{C}$, the active surface of the Al-Si-coated boron steel led to the severe galling, whilst a mild specific galling coefficient and polishing of the pin surface were observed at $600{ }^{\circ} \mathrm{C}$. The galling growth on the specimen surface during the extended sliding distance was not linear and this
Fig. 16 Comparison of the worn and unworn pin in the simulation of the tribological test: a displacement of the pin in the loading direction; $\mathbf{b}$ nodal pressure in the centre of the pin leading edge

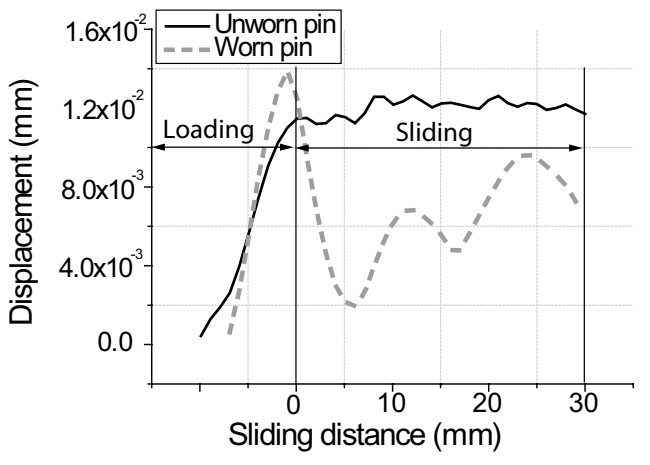

(a)

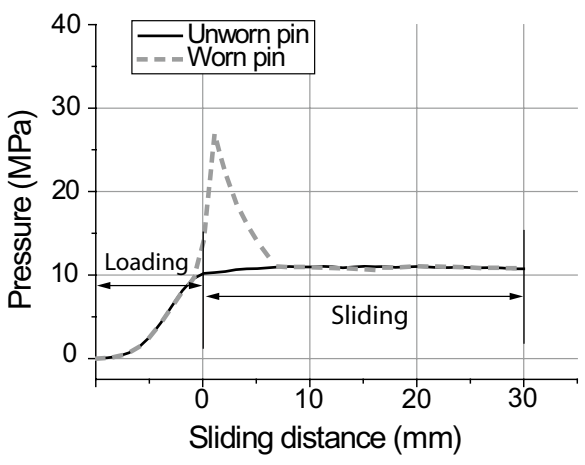

(b) 
may be correlated with the stability and growth rate of the transfer layers. The quantitative measurement of galling is a promising tool for the prediction of galling in press hardening. Based on a simple galling model, the galling distribution was precisely predicted by a FE-simulation. The galling maximum height in the pin surface can be predicted in the simulation using a scale factor on the nominal contact area. The implementation of the geometry updated pin in the numerical model provided the possibility to study the influence of galling on the contact conditions so as to estimate the negative galling effect on the manufacturing process.

Acknowledgements This study was funded by the Swedish Governmental Agency for Innovation Systems, VINNOVA and the FFI-Sustainable Production Technology programme. The authors gratefully acknowledge the supply of specimen material by Gestamp HardTech $\mathrm{AB}$ in Luleå, Sweden.

Open Access This article is distributed under the terms of the Creative Commons Attribution 4.0 International License (http://creativeco mmons.org/licenses/by/4.0/), which permits unrestricted use, distribution, and reproduction in any medium, provided you give appropriate credit to the original author(s) and the source, provide a link to the Creative Commons license, and indicate if changes were made.

\section{References}

1. Åkerström, P., Oldenburg, M.: Numerical simulation of a thermomechanical sheet metal forming experiment. In: Numisheet 2008: Proceedings of the 7th International Conference and Workshop on Numerical Simulation of 3D Sheet Metal Forming Processes, September 1-5, 2008, Interlaken, Switzerland, pp. 569-574. Institute of Virtual manufacturing, ETH Zurich, Zurich (2008)

2. Åkerström, P., Wikman, B., Oldenburg, M.: Material parameter estimation for boron steel from simultaneous cooling and compression experiments. Modell. Simul. Mater. Sci. Eng. 13(8), 1291 (2005)

3. Åkerström, P., Bergman, G., Oldenburg, M.: Numerical implementation of a constitutive model for simulation of hot stamping. Modell. Simul. Mater. Sci. Eng. 15(2), 105-119 (2007)

4. Deng, L., Mozgovoy, S., Hardell, J., Prakash, B., Oldenburg, M.: Development of a tribological test programme based on press hardening simulations. Tribol. Lett. 65(2), 43 (2017)

5. Eriksson, M., Oldenburg, M., Somani, M.C., Karjalainen, L.P.: Testing and evaluation of material data for analysis of forming and hardening of boron steel components. Modell. Simul. Mater. Sci. Eng. 10(3), 277 (2002)

6. Geiger, M., Merklein, M., Lechler, J.: Determination of tribological conditions within hot stamping. Prod. Eng. Res. Dev. 2(3), 269-276 (2008)

7. Ghiotti, A., Bruschi, S., Borsetto, F.: Tribological characteristics of high strength steel sheets under hot stamping conditions. J. Mater. Process. Technol. 211, 1694-1700 (2011)

8. Groche, P., Nitzsche, G.: Influence of temperature on the initiation of adhesive wear with respect to deep drawing of aluminumalloys. J. Mater. Process. Technol. 191(1):314-316 (2007), advances in Materials and Processing Technologies, July 30thAugust 3rd 2006, Las Vegas, Nevada

9. Hardell, J., Pelcastre, L., Prakash, B.: High-temperature friction and wear characteristics of hardened ultra-high-strength boron steel. Proc. Inst. Mech. Eng. J. 224(10), 1139-1151 (2010)
10. Huang, C., Hawbolt, E., Chen, X., Meadowcroft, T., Matlock, D.: Flow stress modeling and warm rolling simulation behavior of two tinb interstitial-free steels in the ferrite region. Acta Mater. 49(8), 1445-1452 (2001)

11. Mori, K., Bariani, P., Behrens, B.A., Brosius, A., Bruschi, S., Maeno, T., Merklein, M., Yanagimoto, J.: Hot stamping of ultrahigh strength steel parts. CIRP Ann. Manuf. Technol. 66(2), 755-777 (2017)

12. LS-DYNA: LS-DYNA 971 User's Manual. Livermore Software Technology Corporation, Livermore (2007)

13. Mozgovoy, S., Hardell, J., Deng, L., Oldenburg, M., Prakash, B.: Effect of temperature on friciton and wear of prehardened tool steel during sliding against 22MnB5 steel. Tribol. Mater. Surf. Interfaces 8(2), 65-73 (2014)

14. Mozgovoy, S., Hardell, J., Deng, L., Oldenburg, M., Prakash, B.: Tribological behaviour of tool steel under press hardening conditions using simulative tests. J. Tribol. 140, 1-11 (2017)

15. Naganathan, A., Penter, L.: Sheet Metal Forming-Processes and Applicaitons, Chapter 7 Hot Stamping, pp. 132-156. ASM International, Materials Park (2012)

16. Nakkalil, R., Hornaday, J., Bassim, M.N.: Characterization of the compression properties of rail steels at high temperatures and strain rates. Mater. Sci. Eng. A 141(2), 247-260 (1991)

17. Pelcastre, L., Hardell, J., Prakash, B.: Investigations into the occurrence of galling during hot forming of Al-Si-coated highstrength steel. J. Eng. Tribol. 225, 487-498 (2011)

18. Pelcastre, L., Hardell, J., Prakash, B.: Galling mechanisms during interaction of tool steel and Al-Si coated ultra-high strength steel at elevated temperature. Tribiol. Int. 67, 263-271 (2013)

19. Pelcastre, L., Hardell, J., Rolland, A., Prakash, B.: Influence of microstructural evolution of al-si coated uhss on its tribological behaviour against tool steel at elevated temperatures. J. Mater. Process. Technol. 228, 117-124 (2016)

20. Petit-Grostabussiat, S., Taleb, L., Jullien, J.F.: Experimental results on classical plasticity of steels subjected to structural transformations. Int. J. Plast. 20(8-9), 1371-1386 (2004)

21. Rudiono, Tomota Y.: Application of the secant method to prediction of flow curves in multi-microstructure steels. Acta Mater. 45(5), 1923-1929 (1997)

22. Schwingenschlögl, P., Weldi, M., Merklein, M.: Investigation of the influence of process parameters on adhesive wear under hot stamping conditions. J. Phys. Conf. Ser. 896(1), 1-8 (2017)

23. Sjömström, S.: The calculation of quench stresses in steel. $\mathrm{PhD}$ thesis, Linköping University (1982)

24. Suehiro, M., Kusumi, K., Maki, J., Ohgami, M., Miyakoshi, T.: Properties of aluminium coated steels for hot forming. Nippon Steel Techn. Rep. 88, 16-21 (2003)

25. Tian, X., Zhang, Y., Li, J.: Investigation on tribological behavior of advanced high strength steels: influence of hot stamping process parameters. Tribol. Lett. 45(3), 489-495 (2012)

26. Wieland, M., Merklein, M.: Parameters influencing adhesive wear behavior within hot stamping operations. In: Oldenburg, M., Prakash, B., Steinhoff, K. (eds.) Proceedings of the 5th International Conference Hot Sheet Metal Forming of High Performance Steel, May 31-June 3, 2015. Verlag Wissenschaftliche Scripten, Zwickau (2015)

27. Yanagida, A., Azushima, A.: Evaluation of coefficients of friction in hot stamping by hot flat drawing test. CIRP Ann. Manuf. Technol. 58(1), 247-250 (2009)

28. Yanagida, Y., Kurihara, T., Azushima, A.: Development of tribosimulator for hot stamping. J. Mater. Process. Technol. 210, 456460 (2010) 